\title{
Sub Lethal Effects of Dichlorvos on Physiological Parameters in Fingerlings of Cyprinus carpio
}

\author{
B. Laxmi ${ }^{1}$, K. Madhavi ${ }^{2}$, A. Adnan ${ }^{3 *}$, B. Chamundeswari Devi ${ }^{1}$, \\ K. Dhanapal ${ }^{1}$ and T.V. Ramana ${ }^{1}$ \\ ${ }^{1}$ College of Fishery Science Muthukur, Nellore, 524344, India \\ ${ }^{2}$ Faculty of Fisheries Rangil, Ganderbal, J\&K, 190006, India \\ ${ }^{3}$ Fisheries Research Station, Kakinada, Andhra Pradesh, 533001, India \\ *Corresponding author
}

\section{A B S T R A C T}

Keywords

Dichlorvos,

Cyprinus carpio,

Sublethal toxicity

and Physiological

changes

Article Info

Accepted:

04 July 2019

Available Online:

10 August 2019
Dichlorvos, one of the extensively used insecticides was investigated in the present study for acute and sublethal toxicity. Fingerlings of common carp (Cyprinus carpio) were selected for the bioassay experiments. The 96 hour $\mathrm{LC}_{50}$ value was found to be $21.11 \mathrm{ppm}$. For sublethal toxicity study two concentrations i.e. $1 / 5^{\text {th }}$ and $1 / 10^{\text {th }}$ of $\mathrm{LC}_{50}$ were selected and semi-static bioassay method was used for 28 days (4 weeks) to observe pesticide induced changes in physiological activities (Feed consumption rate and Ammonia excretion rate). Present result revealed that Dichlorvos exposed fingerlings showed significant decrease in Food consumption rate and significant increase in ammonia excretion rate as compared to control groups. The obtained results indicate that Dichlorvos was toxic to fingerlings of common carp at sub lethal level.

\section{Introduction}

Pesticide contaminations of surface waters have been well documented worldwide and cause a major issue that gives rise to concerns at local, regional, national and global scales due to the adverse effects of pesticide on the environment (Planas et al., 1997). The problem of pesticidal impact on the ecosystem has assumed considerable proportions owing to the modernization of agricultural operations and the consequent widespread and indiscriminate permeation of the ecosystem with pesticides that have resulted in biological stress at all levels of organization not least with respect to fish populations. The pesticides are generally toxic to insects and other animals due to their inhibiting properties of cholinesterase resulting into disruption of cholinergic sites in nervous system (Ghose et al., 1986). There was a shift in the types of insecticides used in the mid 1960's from the 
organochlorine to the less stable organophosphate and carbonate classes ${ }^{3}$. The shift from organochlorines to organophosphates has resulted into increased occurrence of organophosphates into water bodies causing acute and chronic toxicity to fish fauna (Rao et al., 2005; Velmurugan et al., 2007). These are widely used volatile pesticides, many of them are considered hazardous because of their ability to kill or immobilize various organisms at extremely low levels (Eister, 1970). Dichlorvos (DDVP $\mathrm{C}_{4} \mathrm{H}_{7} \mathrm{Cl}_{2} \mathrm{O}_{4} \mathrm{P}$ ) has been used widely as an insecticide since 1961 to control internal and external parasites in livestock and domestic animals, to control insects in houses, and in crop protection. It was first synthesized in the late 1940s (Tinker 1972). Dichlorvos is also a probable mutagen, a neurotoxin and may damage reproduction and development. It is considered to be an acetyl cholinesterase inhibitor. The United States Environmental Protection Agency first considered a ban on DDVP in 1981, since then it has been close to being banned on several occasions, but continues to be available. In the science of aquatic toxicology, fish play an important role in toxicity testing and hazard evaluation, as do the white rat and guinea pig in mammalian toxicology (Anon, 1972), especially teleost fish may be a good indicator of pollution as their biochemical responses are almost similar to that of mammals (Banaee et al., 2008). Common carp is a prime cultured and very important staple freshwater fish generally found in rivers, ponds and reservoirs. It is an economically important fresh water fish, introduced all over the world to form a significant part of freshwater fishery. It is highly palatable and preferred for culture due to its high growth rate and prolific breeding in confined water. Present study was taken up by seeing usage of pesticide Dichlorvos in agriculture sector and importance of the common carp and its availability throughout the water bodies of India.

\section{Materials and Methods}

\section{Test specimen (Test species)}

Common carp (Cyprinus carpio), one of the test specimen as suggested by OCED (1992) for toxicity studies was selected for the experiment.

Test species selection, collection and conditioning

Common carp fingerlings were collected from nearby fish farm and brought to the laboratory in plastic bags with sufficient air. The specimens were about 3-months old with an average body length of $5.7 \pm 0.60 \mathrm{~cm}$ and of body weights $2.1 \pm 0.45 \mathrm{~g}$. Upon arrival at the laboratory, fishes were housed in FRP tanks of 1000 L capacity for 15 days to allow for acclimatization (under the following conditions) prior to pesticide exposure.

The fingerlings were fed twice in every 24 hours with dry pellet feed at the rate of $5 \%$ body weight per day and the excreta was siphoned out daily to prevent buildup of ammonia in the medium.

\section{Test substance}

Test substance used in the present research is dichlorvos as Hyvap ${ }^{\circledR e}$ which consisted of $76 \%$ dichlorvos.

\section{Preparation of stock solution for Dichlorvos toxicity test}

As $1 \mathrm{gm}$ dichlorvos is approximately equal to $0.76 \mathrm{ml}$, so as to prepare $1000 \mathrm{ppm}$ stock solution, we need to have $0.76 \mathrm{ml}$ of dichlorvos in $1000 \mathrm{ml}$ of the solution. As, Hyvap consisted of only 76\% Effective Concentration (EC) of dichlorvos, $1 \mathrm{ml}$ of hyvap contains dichlorvos of $0.76 \mathrm{ml}$. So, $1 \mathrm{ml}$ of Hyvap was added to tap water and finally 
made it to $1 \mathrm{~L}$, so as to have the stock solution of 1000 ppm dichlorvos.

\section{Exploratory test}

Exploratory test otherwise called range finding test, was carried out to assess the approximate effective concentration range of Dichlorvos required for conducting short term test to assess the effect of Dichlorvos on metabolic function of the fish. We carried out range finding acute test (limit tests) with dichlorvos concentrations of 1 ppm, 5 ppm, 10 ppm, $20 \mathrm{ppm}$ and $25 \mathrm{ppm}$ to pinpoint exposure concentrations for the definitive acute test. Based on the results of this ,wide range test ${ }^{\mathrm{ee}}$, a definitive test was carried out in ,narrow range ee $^{\text {eetween }} 15 \mathrm{ppm}$ and $25 \mathrm{ppm}$ concentrations spaced at an interval of $1 \mathrm{ppm}$, so as to generate data, which would be necessary to arrive at $\mathrm{LC}_{50}$ concentration of the test substance (dichlorvos).

\section{Acute toxicity test}

Common carp fingerlings were exposed to definitive concentrations (narrow range) of dichlorvos for a period of 96 hours (as suggested by OECD, 1992) so as to record the concentrations which resulted in a death of $50 \%$ of the fishes exposed. From this data, later $\mathrm{LC}_{50}$ value was estimated following Finney (1971). Test procedure used was Static bioassay method.

\section{Sublethal toxicity test}

The sub-lethal studies were carried out to understand the changes in selected aspects of physiological activities in common carp fingerlings due to exposure to dichlorvos. The sublethal toxicity assay was carried out by selecting two concentrations of $\operatorname{LC}_{50}\left(1 / 10^{\text {th }}\right.$ and $1 / 5^{\text {th }}$ of $\mathrm{LC}_{50}$ ) following semi-static/static renewal bioassay, with three replicates for each selected concentration and control.

\section{Physiological parameters}

Changes in physiological parameters like food consumption rate and ammonia excretion rate were studied for a period of 28 days from the commencement of experiment at weekly intervals in the two selected sublethal concentrations of the toxicant.

\section{Estimation of food consumption rate}

For determining the food consumption rate, the fingerlings were fed once in a day with dry pelleted feed. The left over feed was siphoned out after 30 minutes. The collected feed was dried overnight at $60^{\circ} \mathrm{C}$ in hot air oven and weighed to compare mean food consumption as per the methods of (Broek et al., 1997). Feed intake was estimated as the difference between the given and the remaining weight of feed. Feed was given as per as 5\% body weight of fishes. The food consumption rate was expressed as gm/100 gm body weight of fish.

\section{Estimation of ammonia excretion rate}

Ammonia excretion rate was estimated following phenol hypochlorite method (Sollorzano, 1969). Absorbance was measured spectrophotometrically at $640 \mathrm{~nm}$. Excreted ammonia, by the fish, was calculated as the net difference between the initial and final value of the test period ( 24 hours), corrected by the test chamber capacity and body weight of organisms. Ammonia excretion rate is expressed as $\mu \mathrm{g} / \mathrm{L}$ ammonia/ gram body weight of fish / hour (Huang, 2008).

\section{Statistical analysis}

In sublethal toxicity, responses of fingerling common carp to test conditions i.e., concentration [exposure to control (without dichlorvos, $1 / 10^{\text {th }} \mathrm{LC}_{50}$ and $1 / 5^{\text {th }} \mathrm{LC}_{50}$ ] and exposure duration $[28$ days at 7 days 
intervals], were tested for statistical significance at $\mathrm{p}<0.05$ using two-way ANOVA. Further, the statistical significance of the test (sublethal toxicity) performance was assessed using One-way ANOVA with Duncan Multiple Range test as post hoc. (SPSS version 16.00) taking into consideration of responses (increase or decrease in the observed physiological parameters) of test specimen that were noticed within each treatment including control at weekly intervals during the test tenure.

\section{Results and Discussion}

\section{Food consumption rate}

The data on food consumption, calculated per gram body weight in sublethal concentrations of Dichlorvos for common carp is given in Table 1. Exposure to both sublethal concentrations resulted in decreased food consumption rate and the percentage of decrease was found to be $6.84,17.89,28.95$, $41.05 \%\left(1 / 10^{\text {th }} \quad \mathrm{LC}_{50}\right.$ concentration $)$ and $12.05,30.77,35.90,47.95 \% \quad\left(1 / 5^{\text {th }} \mathrm{LC}_{50}\right.$ concentration) by the end of $1^{\text {st }}, 2^{\text {nd }}, 3^{\text {rd }}$ and $4^{\text {th }}$ quarters respectively. The impaired food consumption rate noticed in toxicant exposure groups compared to control group could be considered as a physiological adaptation to decrease the food intake under toxic environmental conditions to lower the energetic costs of digestion. Moreover, it might be due to the accumulation of nitrogenous metabolite (ammonia) in the medium that have negative impact on appetite as reported by Groves and Kogel (1973). Some of the studies have shown that fish such as silver carp (Piri and Ordog, 1999), Oreochromis mossambicus (Singh et al., 2010), common carp (Muttappa et al., 2013), significant decrease in their food consumption rate in response to variety of pesticides.

\section{Ammonia excretion rate}

Variations in rate of ammonia excreted by fish in control group and fishes exposed to two selected sublethal concentrations observed at weekly intervals during the test tenure (28 days) are presented (Table 2). In sublethal exposures ammonia excretion rate increased significantly with exposure duration and was in the order of $23.08,79.49,125.64,169.23 \%$ $\left(1 / 10^{\text {th }}\right.$ LC $_{50}$ concentration) and $41.46,102.44$, $129.27,185.37 \%\left(1 / 5^{\text {th }} \mathrm{LC}_{50}\right.$ concentration $)$ by the end of $1^{\text {st }}, 2^{\text {nd }}, 3^{\text {rd }}$ and $4^{\text {th }}$ quarters respectively. The reason for increased ammonia excretion by fishes with increase in toxicant concentration and duration might be mainly due to increased protein catabolism. Our results are in agreement with the earlier findings in juvenile Geophagus brasiliensis (Barbieri, 2009), Nile Tilapia (Barbieri and Ferreira, 2011).

Table.1 Alterations in food consumption rate of common carp exposed to sublethal concentrations of "dichlorvos" during experimental period

\begin{tabular}{|c|c|c|c|c|c|}
\hline \multirow{2}{*}{$\begin{array}{c}\text { Test } \\
\text { Condition }\end{array}$} & \multicolumn{5}{|c|}{ Experimental period (Days) } \\
\hline & $\mathrm{D}_{0}$ & $\mathrm{D}_{7}$ & $\mathrm{D}_{14}$ & $\mathrm{D}_{21}$ & $\mathrm{D}_{28}$ \\
\hline Control & $3.95 \pm 0.02 b$ & $3.80 \pm 0.02 \mathrm{a}$ & $3.80 \pm 0.01 \mathrm{a}$ & $3.85 \pm 0.05 a$ & $3.95 \pm 0.02 b$ \\
\hline 1/10th $\mathrm{LC}_{50}$ & $3.80 \pm 0.04 \mathrm{e}$ & $3.54 \pm 0.03 d$ & $3.12 \pm 0.03 \mathrm{c}$ & $2.70 \pm 0.02 b$ & $2.24 \pm 0.03 \mathrm{a}$ \\
\hline 1/5th $\mathrm{LC}_{50}$ & $3.90 \pm 0.06 \mathrm{e}$ & $3.43 \pm 0.02 d$ & $2.70 \pm 0.02 \mathrm{c}$ & $2.50 \pm 0.05 b$ & $2.03 \pm 0.03 \mathrm{a}$ \\
\hline
\end{tabular}


Table.2 Alterations in ammonia excretion rate of common carp exposed to sublethal concentrations of "dichlorvos" during experimental period

\begin{tabular}{|c|c|c|c|c|c|}
\hline \multirow{2}{*}{$\begin{array}{c}\text { Test } \\
\text { Condition }\end{array}$} & \multicolumn{5}{|c|}{ Experimental period (Days) } \\
\cline { 2 - 6 } & $\mathrm{D}_{0}$ & $\mathrm{D}_{7}$ & $\mathrm{D}_{14}$ & $\mathrm{D}_{21}$ & $\mathrm{D}_{28}$ \\
\hline Control & $0.039 \pm 0.001^{\mathrm{ab}}$ & $0.037 \pm 0.001^{\mathrm{a}}$ & $0.039 \pm 0.002^{\mathrm{ab}}$ & $0.041 \pm 0.001^{\mathrm{b}}$ & $0.039 \pm 0.001^{\mathrm{ab}}$ \\
\hline${\mathbf{1 / 1 0 t h ~} \mathbf{L C}_{\mathbf{5 0}}}_{\mathbf{1 / 5} \text { th LC }}$ & $0.039 \pm 0.001^{\mathrm{a}}$ & $0.048 \pm 0.003^{\mathrm{b}}$ & $0.070 \pm 0.001^{\mathrm{c}}$ & $0.088 \pm 0.002^{\mathrm{d}}$ & $0.105 \pm 0.002^{\mathrm{e}}$ \\
\hline $\mathbf{1}^{\mathrm{a}}$ & $0.041 \pm 0.002^{\mathrm{a}}$ & $0.058 \pm 0.004^{\mathrm{b}}$ & $0.083 \pm 0.002^{\mathrm{c}}$ & $0.094 \pm 0.002^{\mathrm{d}}$ & $0.117 \pm 0.002^{\mathrm{e}}$ \\
\hline
\end{tabular}

$\mathrm{D}_{0}, \mathrm{D}_{7}, \mathrm{D}_{14}, \mathrm{D}_{21}$ and $\mathrm{D}_{28}$ represents initial day, 7th day, 14th day, 21st day and 28th day respectively.. The means with different superscript indicates a significant difference $(P<0.05)$. Each value is a Mean $\pm S D(n=3$ replicates).

From the present investigation, it is evident that Dichlorvos $(76 \%$ EC) was toxic to fish and had a profound impact on the food consumption rate and ammonia excretion rate in fingerlings of Cyprinus carpio exposed to sub- lethal concentrations of Dichlorvos.

The findings of present lethal and sublethal toxicity studies would be helpful in framing guidelines to protect aquatic animals against physiological death (i.e., mortality) and ecological death (i.e., unable to function in an ecological context, due to altered biological activities) respectively.

Sublethal toxicity studies of the present research would be useful in strengthening the pool of knowledge that we already have with respect to biological effects of toxicant exposure, mechanism of toxicity determination, besides providing a significant contribution to the data bank on pesticide induced alterations in physiological changes of commercially important, food fishes (like common carp) in both public health and economic point of view in formulating guidelines in support of risk assessment and risk management activities to protect aquatic organisms, though they are completely (except a small fraction of their usage to control external parasites of fishes with respect to their usage in agriculture sector) non-target group with respect to pesticide application.

\section{References}

Anon, 1972. EPA bans most DDT uses; readies lead action. Environmental Science and Technology. 6: 675.

Banaee, M., Mirvagefei, A.R., Rafei, G.R. and Majazi A. B., 2008. Effect of sublethal diazinon concentrations on blood plasma biochemistry. International Journal of Environmental Research. 2: 189-198.

Barbieri, E. and Ferreira, L.A.A., 2011. Effects of the organophosphate pesticide Folidol 600 on the freshwater fish, Nile Tilapia (Oreochromis niloticus). Pesticide Biochem. and Physio., 99(3): 209-214.

Barbieri, E., 2009. Effect of 2, 4-D herbicide (2, 4-dichlorophenoxyacetic acid) on oxygen consumption and ammonium excretion of juveniles of Geophagus brasiliensis (Quoy and Gaimard, 1824) (Osteichthyes, Cichlidae). Ecotox., 18(1): 55-60.

Broek, G.D., Vlaeminck, A. and Blust, R., 1997. Effects of sublethal copper exposure on copper accumulation, food consumption, growth, energy stores, and nucleic acid content in common carp. Arch. Environ. Contam. Toxicol., 33, 415-422.

Eister, R., 1970. Acute toxicities of organochlorine and organophosphorus insecticides to estuarine fishes. U.S. Bur 
Sport Fish. Wildlife Tech., Paper 46.

Finney, D.J., 1971. Probit analysis. 3rd edn. Cambridge University Press, London. pp: 508-510.

Ghose, P., Bhattacharya, S. and Bhattacharya, S., 1986. Impact of non-lethal levels of metacid 50 and carbaryl on thyroid function and cholinergic system of Channa punctatus. Biomed Environ Sc., 5: 18-24.

Groves, W. E. and Kogel, H., 1973. Effects of water volume and change of water on growth and survival of yellow perch. Prog. Fish. Cult. 35 115-117.

Henry, M.G. and Atchison, G.J., 1986. Behavioural changes in social groups of bluegills exposed to copper. Transactions of the American Fisheries Society. 115: 590-595.

Huang, D.J., 2004. Oxygen consumption, ammonia-N excretion, and growth rate in juvenile green-neon shrimp (Neocaridina denticulata) exposed to chlordane and lindane. Acta Zoo. Taiwanica, 14(2): 65-76.

Muttappa, K. Reddy, H.R.V., Mridula R. and Padmanabha, A. 2013. Quinalphos induced alteration in respiratory rate and food consumption of freshwater fish Cyprinus carpio. Journal of Environmental Biology. 12(2): 230-236.

OECD (Organization for Economic Cooperation and Development) (1992). OECD guidelines for testing of chemicals. Fish, Acute Toxicity Test. 203: 1-9.

Piri, M. and Ordog, V., 1999. Effects of herbicides and insecticides on mortality and feeding os silver carp (Hypopthalmichthys molitrix). Iranian Journal of Fisheries Sciences. 1(2): 1121.

Planas, C., Caixach, J., Santos, F.J. and Rivera, J., 1997. Occurrence of pesticides in spanish surface waters. Analysis by high resolution gas chromatography coupled to mass spectrometry. Chemosphere, 34: 23932406.

Rao, J.V., Begum, G., Pallela, R., Usman, P.K. and Rao, R.N., 2005. Changes in behavior and brain acetylcholinesterase activity in mosquito fish, Gambusia affinis in response to the sub-lethal exposure to chlorpyrifos. International Journal of Environmental Research and public health, 2: 478-483.

Singh, R.N., Pandey, R.K., Nath, N. and Das, V.K., 2010. Studied on the acute toxicity and behavioural responses of common carp Cyprinus carpio to organophosphate (dimethoate). World J. Zool., 5: 183-188.

Sollorzano, L., 1969. Determination of ammonia in natural waters by the phenol hypochlorite method. Limnol. Oceanogr., 14: 799.

Tinker, J. (1972) The Vapona dossier. New Sci., 53, 489-492.

Velmurugan, B., Selvanayagam, M., Cengiz, E.I. and Unlu, E., 2007. The effects of monocrotophos to different tissues of freshwater fish Cirrhinus mrigala. Bulletin of Environmental Contamination and Toxicology, 78: 450-454.

\section{How to cite this article:}

Laxmi, B., K. Madhavi, A. Adnan, B. Chamundeswari Devi, K. Dhanapal and Ramana, T.V. 2019. Sub Lethal Effects of Dichlorvos on Physiological Parameters in Fingerlings of Cyprinus carpio. Int.J.Curr.Microbiol.App.Sci. 8(08): 372-377.

doi: https://doi.org/10.20546/ijcmas.2019.808.042 